\title{
Anxiety following traumatic brain injury: Impact on post- hospital rehabilitation outcomes
}

\author{
Gordon J Horn ${ }^{1,4 *}$, Frank D Lewis ${ }^{2}$, Robert Russell ${ }^{3}$ and Dwight Kemp ${ }^{4}$ \\ ${ }^{1}$ NeuroRestorative Research Institute, 3201 Avalon Park Boulevard West Orlando, FL 32828, USA \\ ${ }^{2}$ NeuroRestorative Research Institute, Medical College of Georgia at Augusta University, USA \\ ${ }^{3}$ NeuroRestorative National Clinical Outcomes, Carbondale, IL - USA \\ ${ }^{4}$ Florida State University, College of Medicine, Orlando, FL - USA
}

\begin{abstract}
Background: A need exists to better understand the impact of anxiety on functional outcomes following Traumatic Brain Injury (TBI). Anxiety has been understudied in this population with regard to the impact on functional outcomes within post-hospital rehabilitation settings.

Objectives: To evaluate the prevalence and severity of anxiety among a large group of chronic TBI adults; to determine the impact of anxiety on outcomes of posthospital residential rehabilitation programs; and to assess effectiveness of post-hospital residential rehabilitation programs in treating anxiety.

Methods: The study included 950 adults with moderate to severe traumatic brain injury (TBI). Each subject was assigned to one of four groups based on MPAI- 4 Anxiety ratings: (1) Not Anxious, (2) Mildly Anxious, (3) Moderately Anxious, and (4) Severely Anxious. Functional status was assessed at admission and discharge with the MPAI-4 Participation Index. Differences among groups were evaluated using conventional parametric tests. Rasch analysis established reliability and validity of MPAI-4 data.

Results: Rasch analysis demonstrated satisfactory construct validity and internal consistency (Person reliability = .91-.94, Item reliability $=.99)$. Of the 950 subjects, $46 \%$ presented with moderate to severe anxiety at admission. These subjects demonstrated significantly higher MPAI-4 Participation scores than the mild and not anxious groups. Anxiety groups realized significant improvement in symptoms, but, those remaining anxious at discharge had significantly greater disability than those who improved.
\end{abstract}

Conclusions: Anxiety symptoms had a deleterious impact on post-hospital neurological rehabilitation outcomes. Remediation of symptoms during rehabilitation significantly improved outcomes demonstrating efficacy of post-hospital care.

\section{Introduction}

Anxiety disorders are common comorbidities associated with traumatic brain injury (TBI) [1-3]. As defined by the Centers for Disease Control and Prevention, anxiety disorders have an aggregate 12 month prevalence of $10 \%$ among the general population [4]. Specified anxiety disorders like generalized anxiety, panic, and posttraumatic stress disorders have 12 month prevalence rates of $0.9 \%$ and $2-3 \%, 3.5 \%$, respectively [5].

In contrast, the aggregate incidence of anxiety disorders has been reported up to seven times greater among TBI survivors [6]. Their meta-analysis revealed a prevalence rate of anxiety disorders ranging from $11-70 \%$ in TBI survivors. Similarly, a study reported that $38 \%$ of 100 TBI patients met DSM IV criteria for specified anxiety disorders between 6 months to 5.5 years post-injury with generalized anxiety disorder, panic disorder, and post-traumatic stress disorder occurring at rates of $17 \%, 6 \%$, and $14 \%$, respectively [7]. Additional evidence demonstrated prevalence rates for generalized anxiety disorder, panic disorder, and post-traumatic stress disorder of $9.1 \%, 9.2 \%$ and $14.1 \%$ [8], while others reported $23.8 \%$ (19/80) of TBI outpatients met DSM IV diagnostic criteria for generalized anxiety disorder [9]. TBI patients with specified or unspecified anxiety often report symptoms including persistent worry, tension, and fearfulness. The nature of anxiety symptoms presents significant barriers to participation in neurological rehabilitation and overall recovery following TBI [10]. Given the prevalence of anxiety disorders in this population, research is needed to better understand the impact of this concomitant condition on the course of recovery following a TBI.

The study objectives included: (1) describing prevalence and severity of anxiety among a group of chronically injured TBI adults, (2) examining the impact of anxiety on functional outcomes achieved in post-hospital residential rehabilitation, and (3) evaluating the effectiveness of post-hospital residential rehabilitation programs for improving anxiety symptoms following TBI.

Correspondence to: Gordon J Horn, NeuroRestorative Research Institute, 3201 Avalon Park Boulevard West Orlando, FL 32828, USA; E-mail: gordon.horn@ neurorestorative.com

Key words: anxiety, traumatic brain injury, outcomes, mpai-4, rasch analysis, post-hospital rehabilitation

Received: October 01, 2017; Accepted: October 20, 2017; Published: October 24, 2017 


\section{Methods}

\section{Subjects}

The study sample was selected retrospectively from 1,385 neurologically impaired individuals with consecutive discharges from 32 post-hospital residential rehabilitation programs in 15 states from 2011 to 2016 . From the population of 1,385 , a sample of 950 individuals met study inclusion criteria as follows: diagnosed with a traumatic brain injury, 18 years of age or older, and admitted and discharged from active residential neurorehabilitation. The extent and nature of their disability prevented these participants from living independently. Due to the chronicity of this population, Glasgow Coma Scale scores (GCS) at the scene of injury or upon admission to the trauma center were largely unavailable for review. Therefore, the severity of disability for each participant was determined upon admission to program by assessing the level of impairment with MPAI-4 Total T-scores. This score provides an indication of disability severity level compared to a referenced group of neurologically impaired persons [11].

The mean length of stay for the entire sample was 5.5 months. The mean chronicity of injury (e.g., onset of injury to admission) was 25.91 months. The average age for the total sample was 41.8 years. Detailed demographic characteristics of the sample including MPAI-4 Total $\mathrm{T}$-scores at admission are presented in Table 1.

The MPAI-4 anxiety rating at admission was used to assign participants to one of the four groups: severe anxiety $=17 \%(n=164)$; moderate anxiety $=28 \%(n=269)$; mild anxiety $=25 \%(n=234)$; and no anxiety $=30 \%(n=283)$. The anxiety scale is presented in Table 2 , and the characteristics of participants by group are presented in Table 3.

One way ANOVAs were conducted to determine if the anxiety groups differed on age, length of stay in program, and onset of injury to admission interval. These analyses revealed no significant differences among groups on these factors (Table 3).

Table 1. Sample demographics and injury related variables $(n=950)$.

\begin{tabular}{|l|l|}
\hline Gender & Results \\
\hline Male & $81 \%$ \\
\hline Female & $19 \%$ \\
\hline Age (years) & \\
\hline Mean & 41.8 \\
\hline SD & 14.6 \\
\hline Range & $18-80$ \\
\hline Time Since Injury (months) & \\
\hline Mean & 25.91 \\
\hline SD & 62.27 \\
\hline Range & $1-564.67$ \\
\hline Length of Stay (months) & \\
\hline Mean & 5.5 \\
\hline SD & 7.8 \\
\hline Range & $1-65.5$ \\
\hline Race & \\
\hline African American & $13 \%$ \\
\hline Asian/Pacific & $1 \%$ \\
\hline Caucasian & $74 \%$ \\
\hline Hispanic & $10 \%$ \\
\hline Other & $2 \%$ \\
\hline $\begin{array}{l}\text { Severity of TBI (MPAI-4 Admission Total } \\
\text { T-Score) }\end{array}$ & \\
\hline Mild (< 40) & $3.3 \%$ \\
\hline Mild-moderate (40 - 49) & $20.7 \%$ \\
\hline Moderate (50-59) & $36 \%$ \\
\hline Severe (60+) & $40 \%$ \\
\hline
\end{tabular}

\section{Measures}

The Mayo Portland Adaptability Inventory Version -4 (MPAI-4) [12] provides a useful tool to better understand the impact of anxiety on functional outcome following a TBI. The MPAI-4 is comprised of 29 items assessing the cognitive, physical, and behavioral sequelae following neurologic injury. Raw scores are converted to T-scores within three subscales: Abilities (physical, communication, and cognitive skills), Adjustment (emotional and neurobehavioral skills), and Participation (initiation of activities, social contact, leisure skills, basic and advanced activities of daily living, home skills, paid and unpaid productive activity, and money management). As such, Participation provides a good measure of performance (e.g., application of skills use) and final outcome aim, namely societal participation. The dependent measure used to evaluate functional outcome was the MPAI-4 Participation Index score. Participation scores were converted to T-scores to compare outcomes among the four study groups. Higher scores indicated greater disability (inverse interpretation).

The MPAI-4 is used in post-hospital rehabilitation and has proven reliability, concurrent and predictive validity [11]. Rasch analysis conducted with the MPAI-4 has revealed strong item reliability that demonstrates the independence of the MPAI-4 anxiety scale from other MPAI-4 measures [13]. Given this strong internal reliability, the MPAI- 4 anxiety scale provides a useful means of measuring the impact of anxiety symptoms on neurologic rehabilitative outcomes following TBI.

\section{Rehabilitation treatment}

Post-hospital residential rehabilitation programs are designed to teach generalization of functional skills for return home and greater independence [14]. Admission to these programs commonly occurs 6-12 months or greater after the injury onset [15]. Each participant was admitted to residential neurorehabilitation programs and received physical therapy, occupational therapy, speech therapy, recreation, counseling (based on need), neuropsychological consultation, case management, and medical management provided by nursing and physicians specializing in physical medicine and rehabilitation. Consultation was also provided with Psychiatry and/or Neurology based on individual needs of the participants.

\section{Procedure}

Participants were evaluated upon admission by each program's multidisciplinary treatment team members. Once individual discipline assessments were completed, each participant was then evaluated within two weeks of admission using the MPAI-4 by treatment team consensus. Discharge MPAI-4s were completed in a similar fashion by the treatment team within the final week of the participant's stay. The results of all evaluations were compiled into a national database and combined with participant demographic data. To reduce team scoring bias (e.g., managing reliability), monthly training with the MPAI-4 was provided by experts external to the treating team. To ensure construct validity and item reliability, separate Rasch analyses were conducted on admission and discharge MPAI-4s.

\section{Statistical analysis}

Rasch analysis was conducted for purposes of determining reliability and construct validity of the MPAI-4 as a measure of disability following brain injury. A repeated measures multivariate analysis of co-variance (RM MANCOVA) was provided to evaluate change scores on Abilities, Adjustment, and Participation Indices 
Table 2. MPAI-4 Anxiety Scale (criteria for evaluation) [10]

\begin{tabular}{|l|l|}
\hline Rating & Description: Tense, nervous, fearful, phobic, symptoms of post-traumatic stress disorder such as nightmares, flashbacks of stressful events. \\
\hline 0 None & No complaints or evidence of abnormal tension or anxiety \\
\hline $\begin{array}{l}\text { 1 Mild: no interference with activities. } \\
\text { May use medication. }\end{array}$ & $\begin{array}{l}\text { Infrequent or mild symptoms of tension or anxiety but these do not interfere with activities and usually do not require further evaluation } \\
\text { or treatment. Symptoms do not create a significant disruption in interpersonal or other activities and may appear appropriate reactions to } \\
\text { significant life stress. }\end{array}$ \\
\hline $\begin{array}{l}\text { Mild Problem: interferes with activities } \\
\text { 5-24\% of the time. }\end{array}$ & $\begin{array}{l}\text { Mild anxiety that interferes with some but not the majority of activities. At this level, individuals usually appropriately receive a psychiatric } \\
\text { diagnosis, such as, Adjustment Disorder with Anxiety, PTSD, Anxiety Disorder NOS, or specific phobia. At this level, anxiety most often only } \\
\text { interferes with social or interpersonal activities. }\end{array}$ \\
\hline $\begin{array}{l}\text { Moderate Problem: interferes with } \\
\text { activities 25-75\% of the time. }\end{array}$ & $\begin{array}{l}\text { Anxiety is sufficiently severe to interfere with many activities including vocational activities. As for level 2, these individuals at this level } \\
\text { usually appropriately receive a psychiatric diagnosis. }\end{array}$ \\
\hline $\begin{array}{l}4 \text { Severe Problem: Interferes with } \\
\text { activities more than } 75 \% \text { of the time. }\end{array}$ & $\begin{array}{l}\text { Anxiety is disabling. Examples at this severe level are provided by those who are unable to work or attend school because of anxiety or unable } \\
\text { to leave the house because of severe agoraphobia. }\end{array}$ \\
\hline
\end{tabular}

Malec \& Lezak [10]

Table 3. Demographics for Anxiety Groups.

\begin{tabular}{|c|c|c|c|c|}
\hline Demographic & $\begin{array}{l}\text { Not Anxious } \\
(\mathrm{n}=283)\end{array}$ & $\begin{array}{l}\text { Mildly Anxious } \\
(\mathrm{n}=234)\end{array}$ & Moderately Anxious $(\mathrm{n}=269)$ & Severely Anxious $(\mathrm{n}=164)$ \\
\hline Age & $\begin{array}{l}42.3 \text { (years) } \\
\mathrm{SD}=15.2 \\
\text { Range }=18-80\end{array}$ & $\begin{array}{l}41.0 \text { (years) } \\
\mathrm{SD}=14.8 \\
\text { Range }=18-76\end{array}$ & $\begin{array}{l}41.4 \text { (years) } \\
\mathrm{SD}=14.5 \\
\text { Range }=18-80\end{array}$ & $\begin{array}{l}42.5 \text { (years) } \\
\mathrm{SD}=13.6 \\
\text { Range }=18-74\end{array}$ \\
\hline Gender & $\begin{array}{l}85 \% \text { male } \\
15 \% \text { female }\end{array}$ & $\begin{array}{l}85 \% \text { male } \\
15 \% \text { female }\end{array}$ & $\begin{array}{l}80 \% \text { male } \\
20 \% \text { female }\end{array}$ & $\begin{array}{l}71 \% \text { male } \\
29 \% \text { female }\end{array}$ \\
\hline Time Since Injury & $\begin{array}{l}24.2 \text { (months) } \\
\text { SD } 63.3 \\
\text { Range (1-422) }\end{array}$ & $\begin{array}{l}31.0 \text { (months) } \\
\text { SD } 64.3 \\
\text { Range (1-437) }\end{array}$ & $\begin{array}{l}25.5 \text { (months) } \\
\text { SD 65.2 } \\
\text { Range (1-565) }\end{array}$ & $\begin{array}{l}22.1 \text { (months) } \\
\text { SD 51.8 } \\
\text { Range (1-318) }\end{array}$ \\
\hline Length of Stay & $\begin{array}{l}5.3 \text { (months) } \\
\text { SD } 7.7 \\
\text { Range (1-65.5) }\end{array}$ & $\begin{array}{l}5.6 \text { (months) } \\
\text { SD } 7.6 \\
\text { Range (1-48.1) }\end{array}$ & $\begin{array}{l}5.7 \text { (months) } \\
\text { SD } 8.1 \\
\text { Range (1-58.9) }\end{array}$ & $\begin{array}{l}5.6 \text { (months) } \\
\text { SD } 8.1 \\
\text { Range (1-57.7) }\end{array}$ \\
\hline $\begin{array}{l}\text { Severity (MPAI-4 Participation } \\
\text { T-Score at Admission) }\end{array}$ & $\begin{array}{l}\text { Mild- } \\
\text { Moderate }=52.5 \% \\
\text { Moderate }=37.9 \% \\
\text { Severe }=\quad 9.2 \%\end{array}$ & $\begin{array}{l}\text { Mild- } \\
\text { Moderate }=37 \% \\
\text { Moderate }=45.1 \% \\
\text { Severe }=\quad 17.9 \%\end{array}$ & $\begin{array}{l}\text { Mild- } \\
\text { Moderate }=19.7 \% \\
\text { Moderate }=55.6 \% \\
\text { Severe }=\quad 24.7 \%\end{array}$ & $\begin{array}{l}\text { Mild- } \\
\text { Moderate }=10.9 \% \\
\text { Moderate }=44.5 \% \\
\text { Severe }=\quad 44.6 \%\end{array}$ \\
\hline
\end{tabular}

Group differences in length of stay, $\mathrm{F}(3,946)=.08, \mathrm{p}=.97$, n.s.

Group differences in time since injury, $\mathrm{F}(3,946)=.79, \mathrm{p}=.50$, n.s.

Group differences in age, $\mathrm{F}(3,946)=.52, \mathrm{p}=.67$, n.s.

from admission to discharge. Conventional post-hoc analyses were performed for further clarification of results for each of the study groups (e.g., levels of Anxiety) at admission and discharge and the significance of improvement from admission to discharge. Analyses were performed using SPSS version 22. Rasch Analysis was completed using Winsteps version 3.81 .

\section{Results}

\section{Reliability and validity of MPAI-4}

Rasch analysis was conducted for purposes of determining reliability and construct validity of the MPAI-4 as a measure of disability following brain injury [16]. The model compares expected from the actual values of an item. More specifically, this analysis has been used to demonstrate two important concepts with measures such as the MPAI-4: item and person fit. According to prior research, this analysis "has been used to evaluate how items contributing to a measure represent the underlying construct, and how well the items provide a range of indicators that reliably differentiate among people rated with the measure" [12]. In the current study, Rasch Infit and Outfit statistics were utilized to demonstrate the fit of each item representing unique contribution to the level of disability for individuals being evaluated in the post-hospital setting. Infit values that are nearest to 1.0 indicate minimal distortion, and values between +0.5 and +1.5 are considered productive for measurement use [17]. Other key measures are Person and Item Reliability and Person and Item Separation. Person Reliability indicates how well a measure's items distinguish among individuals (e.g. those possessing a lot or a little of the construct measured). Item Reliability refers to whether test items relate to each other in a consistent way in describing a disparate group of individuals. A coefficient of .80 or greater is considered acceptable for Person Reliability, while a coefficient of at least .90 is optimal for Item Reliability [16]. Separation values indicate "the extent to which items distinguish among people (Person Separation) and are distinct from each other (Item Separation)" (p. 483) [11]. According to that research, a separation of 2.00 or greater is an acceptable value for statistical distinction.

The results of the Rasch analyses demonstrate that the item of Anxiety is in fact a unique contributor to overall disability and reliably differentiates persons with different levels of anxiety contributing to the effect of rehabilitation outcome. These findings can be viewed in Table 4 demonstrating the specific item of anxiety, and additional items found in the Mayo Portland that describe the symptoms that have been associated with anxiety using the Diagnostic and Statistical Manual of Mental Disorders [18].

The results clearly identified the distinction between the item of anxiety and other items within the MPAI- 4 based on Infit and Outfit values at admission and discharge from rehabilitation. In addition, item and person reliability, along with person separation and internal consistency were achieved at acceptable levels and comparable to the 
Table 4. Rasch indicators of reliability and separation for MPAI-4 Admission and Discharge, and select items.

\begin{tabular}{|c|c|c|c|c|}
\hline \multirow[t]{2}{*}{ ITEM } & \multicolumn{2}{|c|}{ Admission MPAI-4 } & \multicolumn{2}{|c|}{ Discharge MPAI-4 } \\
\hline & Infit Value & Outfit Value & Infit Value & Outfit Value \\
\hline Anxiety & 1.13 & 1.18 & 1.15 & 1.20 \\
\hline Attention & .66 & .67 & .62 & .62 \\
\hline Memory & .74 & .73 & .70 & .72 \\
\hline Novel Problem & .66 & .66 & .59 & .58 \\
\hline Depression & 1.08 & 1.15 & 1.10 & 1.12 \\
\hline Fatigue & .89 & .89 & .88 & .88 \\
\hline Initiation & .84 & .81 & .76 & .75 \\
\hline Irritability & 1.22 & 1.21 & 1.18 & 1.17 \\
\hline \multicolumn{2}{|c|}{ Admission MPAI-4 Rasch Statistic } & \multicolumn{3}{|c|}{ Discharge MPAI-4 Rasch Statistic } \\
\hline \multicolumn{2}{|c|}{ Person Separation: 3.15} & \multicolumn{3}{|c|}{ Person Separation: 4.10} \\
\hline \multicolumn{2}{|c|}{ Person Reliability: 0.91} & \multicolumn{3}{|c|}{ Person Reliability: 0.94} \\
\hline \multicolumn{2}{|c|}{ Item Separation: 18.15} & \multicolumn{3}{|c|}{ Item Separation: 18.95} \\
\hline \multicolumn{2}{|c|}{ Item Reliability: 0.99} & \multicolumn{2}{|c|}{ Item Reliability: } & 0.99 \\
\hline
\end{tabular}

MPAI-4 analysis conducted previously [12]. Based on these Rasch findings, the anxiety item provides a unique contribution to the measure of disability and distinguishes between those with and without anxiety that has a functional impact on rehabilitation outcome.

\section{Prevalence and impact of anxiety at admission}

The first goal of the research was to demonstrate the prevalence of anxiety within this post-hospital traumatic brain injury group. As shown in Table 3,164 or $17 \%$ of the study participants were rated to be severely anxious, meaning anxiety symptoms precluded meaningful participation in routine productive activities. Another $269(28 \%)$ participants were rated as moderately anxious. For these participants anxiety was assessed to interfere with performance of everyday activities ranging $25-75 \%$ of the time. Taken together, $45 \%$ of participants experienced anxiety sufficiently severe to receive a psychiatric diagnosis. Another 234 (25\%) exhibited mild anxiety symptoms interfering with activities up to $24 \%$ of the time. Only 283 (30\%) of the study population were considered to not experience any debilitating symptoms of anxiety.

To better understand how the anxiety groups differed at admission with regard to disability (e.g., impact), a between groups one-way ANOVA was conducted on admission MPAI-4 Participation T-scores (performance measure). This analysis revealed a significant main effect for anxiety group $\mathrm{F}(3,946)=31.31, \mathrm{p}<.0005$. The results of post hoc LSD paired comparisons are presented in Table 5.

These findings show that the severely anxious group differed significantly from each of the other three anxiety groups, $p<.001$. The moderately anxious group differed from the no anxiety group, $\mathrm{p}<.001$ and the mildly anxious group, $\mathrm{p}<.01$. The mildly anxious group was not significantly different from the no anxiety group. The impact of anxiety on performance at admission is shown in Figure 1.

Figure one illustrates that as anxiety level increases there is a concomitant increase in Participation T-Scores, clearly describing how anxiety magnifies disability at admission, presenting challenges to recovery.

\section{Impact of anxiety on rehabilitation outcome}

A Repeated Measures (2x4) mixed design ANOVA was performed to examine mean differences among anxiety groups from admission to discharge on MPAI-4 Participation T-scores. This analysis revealed a significant main effect for pre-post testing, Pillai's Trace $=.49, \mathrm{~F}=892$, df $=(1,946), \mathrm{p}=.0005$, partial eta ${ }^{2}=.49$. Each of the anxiety groups showed significant functional improvement from admission to discharge as measured by Participation T-scores. Table 6 presents the means and standard deviations for these scores at admission and discharge for the four anxiety groups.

This analysis also revealed a significant effect for anxiety group, $\mathrm{F}$ $(3,946)=27.19, \mathrm{p}<.0005$, partial eta ${ }^{2}=.08$. Given this significant effect for anxiety, post hoc LSD comparisons were conducted on all possible pairwise contrasts. The severe anxiety group differed significantly from each of the other three groups. The moderate group was significantly different from no anxiety group but not the mild group. The mild group differed significantly from the no anxiety group. Table 7 presents the mean differences and significant levels for each group comparison.

Taken together, these findings demonstrate the adverse impact that anxiety has on functional outcome but also reveal that even those in the most severely anxious group achieved significant reduction in disability and improved functional performance. Admission to discharge improvement by group is illustrated in Figure 2.

\section{Effectiveness of post-hospital treatment: Anxiety admission to discharge}

The third objective of this study was to determine effectiveness of post-hospital brain injury rehabilitation in reducing symptoms of anxiety as part of the therapeutic milieu. An examination of MPAI4 anxiety ratings at admission and discharge for those 164 subjects in the severely anxious group revealed that the ratings declined from 4.0 (severe anxiety) to an average of 2.7 (mild to moderately anxious). A paired-sample T-test revealed this difference to be statistically significant, $\mathrm{t}(163)=13.05 \mathrm{p}<.0005$. Of the 164 individuals rated as severely anxious, 120 subjects (73\%) improved. More specifically, 59 subjects ( $49 \%$ of the group) improved one level to moderately anxious, 38 subjects ( $32 \%$ of the group) improved two levels to mildly anxious, while 23 subjects (19\% of the group) improved three levels to not anxious.

Table 5. Post-hoc LSD paired comparison mean differences on MPAI-4 Admission Participation T-Scores by anxiety groups.

\begin{tabular}{|l|l|l|l|l|}
\hline \multicolumn{6}{|l|}{ Mean Difference on MPAI-4 Admission Participation T-Scores } \\
\hline Anxiety Group & $(1)$ & $(2)$ & $(3)$ & $(4)$ \\
\hline (1) Not Anxious & - & .57 & $2.94^{* *}$ & $8.71^{* *}$ \\
\hline (2) Mildly Anxious & .57 & - & $2.37^{*}$ & $8.14^{* *}$ \\
\hline (3) Moderately Anxious & $2.94^{* *}$ & $2.37^{*}$ & - & $5.77^{* *}$ \\
\hline (4) Severely Anxious & $8.71^{* *}$ & $8.14^{* *}$ & $5.77^{* *}$ & - \\
\hline
\end{tabular}

Significance Values $=* \mathrm{p}<.01, * * \mathrm{p}<.001$

Table 6. Means and Standard Deviations for MPAI-4 Participation T-scores at Admission and Discharge by Anxiety group.

\begin{tabular}{|c|c|c|}
\hline \multicolumn{3}{|c|}{ Participation T- score } \\
\hline Anxiety Group & Admission Mean(SD) & Discharge Mean (SD) \\
\hline Not Anxious & $53.07(10.42)$ & $45.34(11.41)$ \\
\hline Mildly Anxious & $53.64(9.57)$ & $48.25(10.89)$ \\
\hline Moderately Anxious & $56.01(9.29)$ & $49.15(10.04)$ \\
\hline Severely Anxious & $61.78(9.84)$ & $53.54(11.78)$ \\
\hline
\end{tabular}

Table 7. LSD pair wise comparisons for mean differences between anxiety groups on MPAI -Participation T-scores admission to discharge.

\begin{tabular}{|c|c|c|c|c|}
\hline Anxiety Group & $(1)$ & $(2)$ & $(3)$ & $(4)$ \\
\hline Not Anxious & - & $1.74 *$ & $3.37 * * *$ & $8.45^{* * *}$ \\
\hline Mildly Anxious & $1.74^{*}$ & - & 1.63 & $6.71 * * *$ \\
\hline Moderately Anxious & $3.37^{* * *}$ & 1.63 & - & $5.08^{* * *}$ \\
\hline Severely Anxious & $8.45^{* * *}$ & $6.71 * * *$ & $5.08^{* * *}$ & - \\
\hline
\end{tabular}

${ }^{*} \mathrm{p}<.05 ; * * \mathrm{p}<.01 ; * * * \mathrm{p}<.001$ 
Admission MPAI-4 Participation T-scores by Anxiety Group

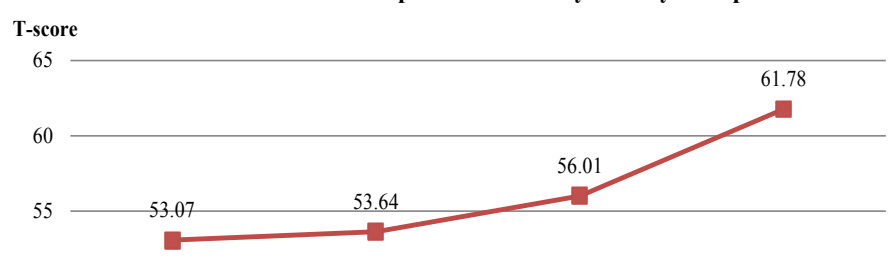

50

45

40

No Anxiety Mild Anxiety Moderate Anxiety Severe Anxiety

Figure 1. Impact of Anxiety on performance at Admission.

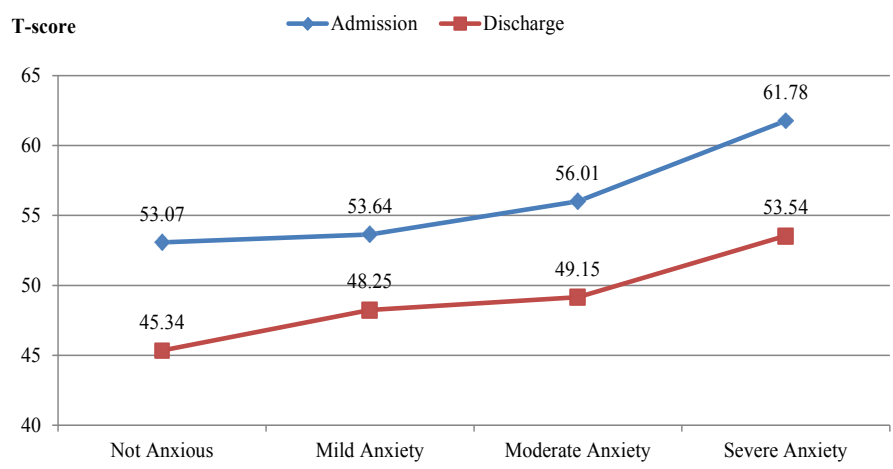

Figure 2. Admission to discharge Participation T-scores by anxiety group*.

Similarly, a paired-samples T-test conducted on the moderately anxious group showed a significant reduction in anxiety ratings from 3.0 at admission to a mean score of 2.07 at discharge $t(268)=16.89$ $\mathrm{p}<.0005$. Of the 269 individuals rated as moderately anxious, 102 subjects (38\% of the moderate group) improved one level to mildly anxious, 55 subjects ( $20 \%$ of the moderate group) improved two levels to not anxious, but 8 subjects ( $3 \%$ of the moderate group) worsened to the severely anxious category.

Next, follow-up analyses were performed to determine if the reduction in anxiety resulted in improved functional outcomes. The 164 severely anxious subjects were divided into two groups based on discharge MPAI-4 anxiety scores. One group was comprised of 61 individuals who improved to ratings of mildly anxious or not anxious. The second group included 103 who remained moderately $(n=59)$ or severely anxious $(n=44)$. An independent samples t-test was performed to examine differences between the groups on functional performance as measured by the MPAI-4 Participation T-score at discharge. This analysis revealed significant group differences $\mathrm{t}(162)=4.5, \mathrm{p}<.0005$. The mean discharge Participation T-scores were 56.55 (moderate severe group) vs 48.44 (mild - not anxious group). On average, those experiencing no more than mild symptoms of anxiety demonstrated greater independence in performing everyday functional tasks than those experiencing moderate to severe symptoms. Of note, mean Participation T-scores differences were not statistically significant for these groups at admission, independent $\mathrm{t}$-test, $\mathrm{t}(162)=1.27$ n.s., again indicating the adverse impact of anxiety on functional outcomes. When anxiety abated, functional independence significantly improved. It is also important to note that it is common for persons recovering from TBI to experience increased anxiety as they gain awareness of their circumstances and the extent of their injury impact. An examination of the 234 mildly anxious subjects revealed that 16 subjects (7\%) experienced a worsening of symptoms. At discharge from program, 11 subjects (5\%) of these subjects increased to ratings of moderate anxiety while 5 subjects (2\%) were rated as severely anxious. Similarly of the 283 subjects in the not anxious group, at discharge 20 subjects (7\%) were rated mildly anxious, 7 subjects (2\%) moderately anxious, and 3 subjects (1\%) severely anxious.

\section{Discussion}

Consistent with prior research [12], the MPAI-4 was found to be psychometrically sound and a reasonable measure to evaluate the impact of disability and performance of skills following traumatic brain injury. Further, the current study supported the statistical properties established earlier with the MPAI-4 that demonstrated the instrument is able to measure independent and unique factors contributing to brain injury recovery. Anxiety was one facet that was measured and evaluated within the current study using this instrument.

Consistent with previous research as well, this study found a high rate of anxiety among a chronic group of TBI survivors. Prior research estimated a range between $20-70 \%$ of TBI survivors experiencing symptoms of anxiety as part of recovery and restoration of function at the post-hospital level [6]. Of the 950 current study participants, $45 \%$ experienced anxiety symptoms sufficient to merit a psychiatric diagnosis upon admission to the program. The study also demonstrated a more chronic group being evaluated with an average of approximately 28 months from the time of injury to measurement at admission.

Rasch analyses conducted on the MPAI-4 rating scales demonstrated that the prevalence of anxiety was not inflated by injury induced cognitive and neurobehavioral impairments whose symptoms may mirror anxiety. The impact of anxiety on overall function was clear. As anxiety ratings increased, so did the level of overall disability. Those in the moderate and severe anxiety groups experienced higher levels of disability and poorer functional performance than the mild and not anxious groups as measured by MPAI-4 Participation T-scores at admission and discharge respectively. Outcomes for those in the severely anxious group were significantly more disabled than those in each of the other three groups.

An additional important finding of this study was that the participants in each of the four anxiety groups realized improved functional independence following completion of post-hospital residential rehabilitation programs despite averaging greater than 2 years since the time of injury to admission. In each of the groups, MPAI-4 T-scores were significantly lowered (less disability) from admission to discharge, a result achieved even in the severely anxious group suggesting the effect of a multidisciplinary post-hospital approach. This finding is also consistent with prior research indicating that after approximately 8 months of recovery, improvement is based on intervention rather than spontaneous recovery effects [19].

Aside from improved disability and improved performance, the programs were also effective with reducing the impact of anxiety symptoms. The percentage of persons with moderate to severe anxiety ratings dropped from $45 \%$ at admission to $24 \%$ at discharge, a rate much lower than the prevalence reported in the literature for chronic TBI survivors. Nonetheless, for those remaining anxious, their outcomes were poorer than those who improved by discharge. The analysis of the severe anxiety group revealed that 103 of the 164 participants continued to experience moderate to severe symptoms of anxiety at discharge. These participants experienced far worse outcomes than the 
61 participants in the severe group who improved to the mildly anxious or not anxious category. There were no significant differences between these two sub-groups (severe) using the same measure at admission, suggesting that anxiety was an important contributor to the difference in outcome performance. The 61 participants within the severe anxiety group that improved to the mild level at discharge averaged a discharge Participation T-score of 48.54 . This score was equivalent to the mean discharge Participation T-score of 48.25 achieved by the mild anxiety group. This finding is illustrative of the impact of anxiety on functional outcomes and emphasizes the importance of treating anxiety to maximize the effectiveness of post-hospital residential rehabilitation programs.

The finding that anxiety has an adverse impact on outcome following TBI is not surprising. Success in post-hospital brain injury rehabilitation requires active participation in rigorous therapies. Symptoms of anxiety (e.g. worry, fear, irritability, difficulty concentrating, and fatigue) present significant barriers to such participation. Therefore, if not addressed, rehabilitative outcomes may be negatively altered. It is encouraging that many participants who began rehabilitation ranging from moderate to severe anxiety ratings showed significant improvement with anxiety at discharge and this improvement was associated with greater functional independence.

\section{Limitations}

The researchers were unable to determine the percentage of anxious participants who were anxious premorbidly. For example, those in the severe anxiety group who continued with high levels of anxiety (e.g., no positive change in symptom presentation) may have been related to a more chronic anxiety history premorbidly than those who changed from severe anxiety to less. In addition, the researchers were unable to determine the impact of treatment complexity (e.g., counseling, medication, or both) on anxiety levels at discharge. Finally, this study concluded as each subject was discharged from the respective programs. A long-term follow-up may be indicated to evaluate the durability of the reduction in anxiety and disability post-discharge.

\section{Conclusions}

Anxiety has been considered a public health problem across the world populations with negative effects impacting physical wellbeing and level of functioning for those without neurological injury. The current study demonstrated the negative impact of anxiety on neurological rehabilitation outcomes. Remediation of primary and residual effects of anxiety during rehabilitation significantly improved outcomes, leading to reduced disability with a positive societal impact.

\section{Declaration of interest}

Three of the authors are employed by NeuroRestorative who provided financial support for this research. The authors' employers were not aware of the study's findings at the time of submission. The fourth author is a student within the Florida State University, College of Medicine and has no financial disclosure.

\section{References}

1. Koponen S, Taiminen T, Portin R, Himanen L, Isoniemi H, et al (2002) Axis I and II psychiatric disorders after traumatic brain injury: a 30-year follow-up study. $\mathrm{Am} \mathrm{J}$ Psychiatry 159: 1315-1321. [Crossref]

2. Hiott DW, Labbate L (2002) Anxiety disorders associated with traumatic brain injuries NeuroRehabilitation 17: 345-355. [Crossref]

3. Hibbard MR, Uysal S, Kepler K, Bogdany J, Silver J (1998) Axis I psychopathology in individuals with traumatic brain injury. J Head Trauma Rehabil 13: 24-39. [Crossref]

4. Kessler RC, Aguilar-Gaxiola S, Alonso J, Chatterji S, Lee S, et al (2009) The global burden of mental disorders: an update from the WHO World Mental Health (WMH) surveys. Epidemiol Psichiatr Soc 18: 23-33. [Crossref]

5. Kessler RC, Chui WT, Demler O, Walters EE (2005) Prevalence, severity, and comorbidity of 12-months DSM-IV disorders in the National Comorbidity Survey Replication. Arch Gen Psychiatry 62: 617-627. [Crossref]

6. Chaudhury S, Biswas PS, Kumar S. Psychiatric sequelae of traumatic brain injury (2013) Medical J Dr. DY Patil University 6: 222-228.

7. Whelan-Goodinson R, Ponsford J, Johnston L, Grant F (2009) Psychiatric disorders following traumatic brain injury: Their nature and frequency. J Head Trauma Rehabil 24: 324-332. [Crossref]

8. Van Reekum R, Cohen T, Wong J (2000) Can traumatic brain injury cause psychiatric disorders?. J Neuropsychiatry Clin Neurosci 12: 316-327. [Crossref]

9. Mooney G, Speed J (2001) The association between mild traumatic brain injury and psychiatric conditions. Brain Inj 15: 865-877. [Crossref]

10. Mooney G, Speed J, Sheppard S (2005) Factors related to recovery after mild traumatic brain injury. Brain Inj 19: 975-987. [Crossref]

11. Malec JF, Kragness M, Evans RW, Finlay KL, Kent A (2003) Further psychometric evaluation and revision of the Mayo-Portland Adaptability Inventory in a national sample. J Head Trauma Rehabil 18: 479-492. [Crossref]

12. Malec JF, Lezak MD (2008) The Mayo-Portland Adaptability Inventory (MPAI-4) for adults, children and adolescents. Manual 1-84.

13. Lewis FD, Horn GJ (2017) Depression following traumatic brain injury: impact on post-hospital residential rehabilitation outcome. NeuroRehabilitation 40: 401-410. [Crossref]

14. Dixon TP. Systems of care for the head-injured (1989) Phys Med Rehab: State of the Art Reviews 3: 169-181.

15. Lewis FD, Horn GJ (2015) Neurologic continuum of care: Evidence-based model of a post-hospital system of care. NeuroRehabilitation 36: 243-251. [Crossref]

16. Bond T, Fox CM (2001) Applying the Rasch Model: Fundamental Measurement in the Human Sciences. Mahwah, NJ: Erlbaum.

17. Linacre J (2002) What do Infit and Outfit, mean-squared and standardized mean? Arch of Rasch Measurement 16: 871-882.

18. American Psychiatric Association (2013) Diagnostic and Statistical Manual of Mental Disorders $5^{\text {th }}$ Edition (DSM 5). Arlington, VA: American Psychiatric Publishing.

19. Lewis FD, Horn GJ (2013) Traumatic Brain Injury: Analysis of Functional Deficits and Post-hospital Rehabilitation Outcomes. J Spec Oper Med 13: 56-61. [Crossref]

Copyright: (C2017 Horn GJ. This is an open-access article distributed under the terms of the Creative Commons Attribution License, which permits unrestricted use, distribution, and reproduction in any medium, provided the original author and source are credited. 